\title{
Graphite Screen-Printed Electrodes Applied for the Accurate and Reagentless Sensing of $\mathrm{pH}$
}

\author{
Flávia E. Galdino, ${ }^{\dagger \neq}$ Jamie P. Smith, ${ }^{\ddagger}$ Sophie I. Kwamou, ${ }^{\S}$ Dimitrios K. Kampouris, ${ }^{\ddagger}$ Jesus Iniesta,"
} Graham C. Smith, ${ }^{\perp}$ Juliano A. Bonacin, ${ }^{\dagger}$ and Craig E. Banks* ${ }^{*}+$

${ }^{\dagger}$ Institute of Chemistry, University of Campinas-UNICAMP, P.O. Box 6154, 13083-970, Campinas, São Paulo Brazil

${ }^{\ddagger}$ Faculty of Science and Engineering, School of Science and the Environment, Division of Chemistry and Environmental Science, Manchester Metropolitan University, Chester Street, Manchester M1 5GD, U.K.

${ }^{\S}$ Université Paris-Est Créteil-Val de Marne, Faculté des Sciences et Technologie, 61 Avenue du Général de Gaulle, 94010 Créteil Cedex France

"Physical Chemistry Department and Institute of Electrochemistry, University of Alicante,03690, San Vicente del Raspeig, Alicante Spain

${ }^{\perp}$ Faculty of Science and Engineering, Department of Natural Sciences, University of Chester Thornton Science Park, Pool Lane, Ince, Chester $\mathrm{CH} 2$ 4NU, U.K.

\section{Supporting Information}

ABSTRACT: A reagentless $\mathrm{pH}$ sensor based upon disposable and economical graphite screen-printed electrodes (GSPEs) is demonstrated for the first time. The voltammetric $\mathrm{pH}$ sensor utilizes GSPEs which are chemically pretreated to form surface immobilized oxygenated species that, when their redox behavior is monitored, give a Nernstian response over a large $\mathrm{pH}$ range $(1-13)$. An excellent experimental correlation is observed between the voltammetric potential and $\mathrm{pH}$ over the entire $\mathrm{pH}$ range of $1-13$ providing a simple approach with which to monitor solution $\mathrm{pH}$. Such a linear response over this dynamic $\mathrm{pH}$ range is not usually expected but rather deviation from linearity is encountered at alkaline $\mathrm{pH}$ values; absence of this has previously been attributed to a change in the $\mathrm{p} K_{\mathrm{a}}$ value of surface immobilized groups from that of solution phase species. This non-deviation, which is observed here in the case of our facile produced reagentless $\mathrm{pH}$ sensor and also reported in the literature for $\mathrm{pH}$ sensitive compounds immobilized upon carbon electrodes/surfaces, where a linear response is observed over the entire $\mathrm{pH}$ range, is explained alternatively for the first time. The performance of the GSPE $\mathrm{pH}$ sensor is also directly compared with a glass $\mathrm{pH}$ probe and applied to the measurement of $\mathrm{pH}$ in "real" unbuffered samples where an excellent correlation between the two protocols is observed validating the proposed GSPE $\mathrm{pH}$ sensor.

$\mathrm{T}^{\mathrm{k}}$ he accurate measurement of $\mathrm{pH}$ is crucial to a diverse array of scientific fields, ${ }^{1,2}$ where, for example, the slightest fluctuation can potentially result in substantial changes to the kinetics of a reaction. ${ }^{3,4}$ From the online monitoring of proton ions in extreme conditions, such as those postured by a nuclear reactor to wastewater treatment plants and the observing of blood $\mathrm{pH}$ by clinicians, ${ }^{1,2}$ the determination of $\mathrm{pH}$ is vital.

Typical approaches for the measurement of $\mathrm{pH}$ are based upon electrochemical methods but face issues that need to be overcome. The most commonly used technique, potentiometric glass electrodes, have a limited shelf life due to the degradation of the glass membrane and the fragility that is associated with glass. In addition, the glass membrane $\mathrm{pH}$ electrodes have significant inaccuracy at high $\mathrm{pH}$ values, ${ }^{5}$ a so-called "alkali error" and regular calibration of the $\mathrm{pH}$ sensor is necessary as a pretreatment; consequently they have little potential of the development into a portable hand-held device or be used easily in-the-field. ${ }^{2,5}$
A different approach for the $\mathrm{pH}$ measurement of a solution is based again on the application of electrochemical techniques; however, they instead involve the use of voltammetric techniques. ${ }^{3,4,6-8}$ In this case, a $\mathrm{pH}$ dependent mediator is selected $^{9-12}$ and its electrochemical activity is monitored (reduction or oxidation). A popular choice is quinone moieties which have been utilized previously in the literature, for example, a carbon-epoxy electrode with $\mathrm{pH}$ sensitive species anthraquinone and phenanthrenequinone ${ }^{11}$ and the modification of a glassy carbon electrode with an anthraquinoneferrocene film have been reported. ${ }^{13}$ In such instances, the peak potential $\left(E_{\mathrm{p}}\right)$ of the redox peak is dependent on the $\mathrm{pH}$ of the solution in which the mediator is present (as per the Nernst equation), and while using potentially cheaper electrodes and no further specialist equipment (such as a $\mathrm{pH}$ meter) it could

Received: April 1, 2015

Accepted: November 2, 2015

Published: November 12, 2015 
prove to be a cost-effect approach to $\mathrm{pH}$ sensing. Using a voltammetric method requires quantification of $\mathrm{pH}$ via the Nernst equation $^{14}$ (eq 1$)$ and the measured potential $\left(E_{\mathrm{p}}\right)$ as given by

$$
E_{\mathrm{p}}=E_{\mathrm{f} / \mathrm{Ox} / \mathrm{Red}}^{0}-2.303 \frac{R T}{n F} \log \frac{[\mathrm{Red}]}{[\mathrm{Ox}]}
$$

where $n$ is the number of electrons involved in the reaction, $R$ the ideal gas constant, $T$ is the temperature, $F$ is the Faraday constant, and $E_{\mathrm{f}}^{0}$ is the formal potential of the redox process.

This paper reports the preparation of a voltammetric $\mathrm{pH}$ sensor based upon cost-effective and disposable screen-printed graphite electrodes (GSPEs) which are chemically pretreated to form surface oxygenated species that, when their redox behavior is observed, give rise to a Nernstian response relative to the $\mathrm{pH}$ of the solution and as a result, a quantifiable signal to determine $\mathrm{pH}$. GSPEs are of a benefit because of their robustness, especially when compared to the previously mentioned glass membrane electrodes, low purchase cost, rapid utilization, and simplicity. ${ }^{15-18}$

Previous literature reports the utilization of carbon electrodes (glassy carbon [GC], edge plane pyrolytic graphite [EPPG]) with extensive mechanical polishing (20 min prior to each experiment) to generate oxygenated (quinone) species which monitor $\mathrm{pH}^{3,4}$ It is theorized that a near perfect calibration plot ranging from $\mathrm{pH} 1.0$ to $\mathrm{pH} 13.0$ can be obtained with a Nernstian response corresponding to a 2 proton $/ 2$ electron system, which would relate to the redox processes of the quinone groups upon the electrode surface following extensive polishing. However, it is noticed that surface characterization to confirm such inferences of surface immobilized groups are clearly lacking. Typically, a solution-based mediator undergoing such a reaction will affect the slope of a potential vs $\mathrm{pH}$ plot with a change in linearity occurring at the mediator's $\mathrm{p} K_{\mathrm{a}}$. For example, quinone moieties in solution have a reported $\mathrm{p} K_{\mathrm{a}}$ value of $c a$. 9.2 which would give rise to two linear regions either side of this value over the entire $\mathrm{pH}$ range; however Lu et al., along with other groups, observed no change in linearity when the quinone moiety was bound to the surface of GC and EPPG electrodes. $3,4,19,20$

In this paper, a novel reagentless electrochemical approach using disposable GSPEs that are chemically pretreated to form oxygenated species on the electrode surface for the accurate sensing of $\mathrm{pH}$ utilizing square-wave voltammetry (SWV) is reported for the first time. Such work allows an economical and disposable sensor to be realized that does not need surface modification with quinone-type compounds nor extensive surface pretreatment via mechanical polishing; ${ }^{3,4}$ since the electrodes are chemically pretreated multiple electrodes can be readily prepared at once. The electrochemical response of the GSPEs are explored at different $\mathrm{pHs}$ demonstrating an exceptional linear response from $\mathrm{pH} 1.76$ to 13.12 with a gradient predicting a theoretical shift in reduction potentials of $57 \mathrm{mV}$ per $\mathrm{pH}$ unit, which is in excellent agreement with the value for a Nernstian response of a $1: 1$ proton-electron process $(59 \mathrm{mV}$ per $\mathrm{pH}$ unit, $\mathrm{T}=298 \mathrm{~K})$. The protocol is also validated against the traditional glass $\mathrm{pH}$ probe in the measurement of $\mathrm{pH}$ in "real" unbuffered samples.

\section{EXPERIMENTAL SECTION}

All chemicals used were of analytical grade and were used as received without any further purification from Sigma-Aldrich
(Gillingham, U.K.). All solutions were prepared with deionized water of resistively no-less than $18.2 \Omega \mathrm{cm}$. All solutions (unless stated otherwise) were vigorously degassed with nitrogen to remove oxygen prior to analysis.

Voltammetric measurements were carried out using a $\mu$ AutolabII (Eco Chemie, The Netherlands) potentiostat/ galvanostat and controlled by Autolab GPES software version 4.9. Experiments were performed using screen-printed graphite macroelectrodes (denoted as GSPEs herein) which have a 3 $\mathrm{mm}$ diameter working electrode were fabricated in-house with appropriate stencil designs using a DEK 248 screen-printing machine (DEK, Weymouth, U.K.). For the fabrication of the screen-printed sensors, first, a carbon-graphite ink formulation (product code C2000802P2; Gwent Electronic Materials Ltd., U.K.) used previously was screen-printed onto a polyester (Autostat, $250 \mu \mathrm{m}$ thickness) flexible film (denoted throughout as standard-SPE). This layer was cured in a fan oven at $60 \mathrm{deg}$ for $30 \mathrm{~min}$. Next a $\mathrm{Ag} / \mathrm{AgCl}$ reference electrode was included by screen-printing $\mathrm{Ag} / \mathrm{AgCl}$ paste (product code C2040308D2; Gwent Electronic Materials Ltd., U.K.) onto the polyester substrates. Finally, a dielectric paste (product code D2070423D5; Gwent Electronic Materials Ltd., U.K.) was then screen-printed onto the polyester substrate to cover the connections. After curing at $60 \mathrm{deg}$ for $30 \mathrm{~min}$, the screenprinted electrodes are ready to be used. The reproducibility and repeatability of the batch fabricated screen-printed sensors were found to correspond to a \% relative standard deviation (\% RSD) no greater than $0.82 \%(N=20)$ and $0.76 \%(N=3)$ for the heterogeneous rate constant; $k^{\circ}$ for the $\mathrm{Ru}\left(\mathrm{NH}_{3}\right)^{2+/ 3+}$ redox probe in $1 \mathrm{M} \mathrm{KCl}$ was found to be equal to $1.08 \times 10^{-3} \mathrm{~cm} \mathrm{~s}^{-1}$. Because of the removal of the $\mathrm{Ag} / \mathrm{AgCl}$ reference in forming the surface immobilized oxygenated species, via the proposed chemical pretreatment (see later), an external saturated calomel electrode (SCE) was used as the reference and a platinum counter was also utilized in a three electrode setup; the use of the SCE reference electrode in the evaluation of new $\mathrm{pH}$ sensors/materials is common place in the literature. Independent $\mathrm{pH}$ measurements were performed using a SevenCompact $\mathrm{pH}$ meter (Mettler Toledo) which was calibrated prior to use with $\mathrm{pH}$ standard. The various tested solutions ranged from $\mathrm{pH}$ 1.76 to 13.12 and were composed of $\mathrm{HCl}(\mathrm{pH} \mathrm{1.76)}$, phosphate buffer solution (PBS; pH 2.48, 3.51, 4.29, 6.47, 7.32, 8.26, 9.27, $10.16,11.20,12.10,13.12)$. Real $\mathrm{pH}$ samples consisted of a commonly available antacid (Rennies) and malt vinegar. The antacid (1.3 g) was dissolved in water before analysis, and the malt vinegar was analyzed without any pretreatment or dilution.

The chemical formation of surface groups involved immersion of GSPEs (with $\mathrm{Ag} / \mathrm{AgCl}$ reference removed) into a percarbonate solution $\left([10 \% \mathrm{w} / \mathrm{v}] \mathrm{Na}_{2} \mathrm{CO}_{3} / \mathrm{H}_{2} \mathrm{O}_{2}\right.$, available $\left.\mathrm{H}_{2} \mathrm{O}_{2} 20-30 \%\right)$ and was left overnight $(18 \mathrm{~h})$. Note: electrodes were also left for a longer duration ( $45 \mathrm{~h})$; however, no significant difference in electrochemical response was observed (see Figure S1). This procedure is optimal, meaning that all electrodes pretreated via this approach are successfully prepared.

X-ray photoelectron spectroscopy (XPS) was used to analyze the electrode surface and its hypothesized oxygenated groups. All spectra were collected using a bespoke ultrahigh vacuum system fitted with a Specs GmbH Focus 500 monochromated Al K $\alpha$ X-ray source, Specs GmbH PHOIBOS $150 \mathrm{~mm}$ mean radius hemispherical analyzer with 9-channeltron detection, and a Specs GmbH FG20 charge neutralizing electron gun. Survey spectra were acquired over the binding energy range 1100 to 0 
$\mathrm{eV}$ using a pass energy of $50 \mathrm{eV}$ and high-resolution scans were made over the $\mathrm{C} 1 \mathrm{~s}$ and $\mathrm{O} 1 \mathrm{~s}$ lines using a pass energy of $20 \mathrm{eV}$. The analysis area was approximately $1.4 \mathrm{~mm}$ in diameter. Under these conditions, the full width at half-maximum of the Ag $3 \mathrm{~d}_{5 / 2}$ reference line is $\sim 0.7 \mathrm{eV}$. The energy scale of the instrument is calibrated according to International Organization for Standardization (ISO) standard 15472, and the intensity scale is calibrated using an in-house method traceable to the UK National Physical Laboratory. Data were quantified using Scofield photoelectric cross sections corrected for the energy dependencies of the electron attenuation lengths and the instrument transmission. Data interpretation was carried out using CasaXPS software v2.3.16.

Scanning electron microscope (SEM) micrographs were obtained with a Zeiss Supra 40vp model. Fourier transforminfrared spectroscopy (FT-IR, Nicolet iS5, Thermo Scientific) was performed on the surface with the iD5 ATR-Diamond accessory. Eight scans were performed over the range 4000$525 \mathrm{~cm}^{-1}$ with $1.928 \mathrm{~cm}^{-1}$ data spacing and recorded with a DTGS $\mathrm{KBr}$ detector utilizing a $\mathrm{KBr}$ beam splitter. From this, \% transmittance was obtained and the values were compared to commonly available IR transmittance tables.

\section{RESULTS AND DISCUSSION}

Characterization of the Chemically Pretreated Electrodes. GSPEs were chemically pretreated to form surface immobilized oxygenated species, as detailed in the Experimental Section, which introduces oxygenated species upon the electrode surface. The pretreated GSPES were characterized with scanning electron microscopy (SEM), X-ray photoelectron spectroscopy (XPS), and Fourier transform-infrared spectroscopy (FT-IR). Apparent from the SEM images in Figure 1 is an increase in porosity for the pretreated GSPE (Figure 1B) which is likely the result of the chemical pretreatment with percarbonate solution $\left([10 \% \mathrm{w} / \mathrm{v}] \mathrm{Na}_{2} \mathrm{CO}_{3} / \mathrm{H}_{2} \mathrm{O}_{2}\right)$; (see the Experimental Section). FT-IR and XPS were performed to aid the hypothesized presence of generated oxygenated species immobilized on the electrode surface as a result of the chemical pretreatment process. The chemically pretreated and untreated GSPEs were measured with FT-IR and expecting an increase in peaks in the $1665-1760 \mathrm{~cm}^{-1}$ range for the chemically pretreated GSPE, which would be indicative of carbonyl moiety. However, following experimentation there was found to be no distinct variation between both chemically pretreated and untreated GSPEs; this could be related to the "depth" to which the IR beam penetrates the electrode surface (the generated oxygenated species are only theorized to be on the surface).

The XPS results from the electrodes (Table 1) showed the regular GSPE working electrode surface to be composed of $87.3 \%$ carbon and $3.9 \%$ oxygen with the carbon 1s spectrum of the untreated GSPE typical of an oxidized graphite-like material. The chemically pretreated electrode surface had an increased oxygen content of $16.7 \%$ and a reduced carbon content of $71.1 \%$ indicating oxidation of the electrode surface. The carbon 1s spectra from the pretreated and the reference GSPE samples are shown in Figure S2. In both cases, the spectra show a strong asymmetric and narrow component at approximately $284.8 \mathrm{eV}$ binding energy which is typical of graphitic carbon. They both also show a strong shoulder at approximately $286.3 \mathrm{eV}$. This is due to carbon in either $\mathrm{C}-\mathrm{O}$ or $\mathrm{C}-\mathrm{Cl}$ bonds, which cannot generally be resolved by XPS. However, analysis of the relative intensity of this component

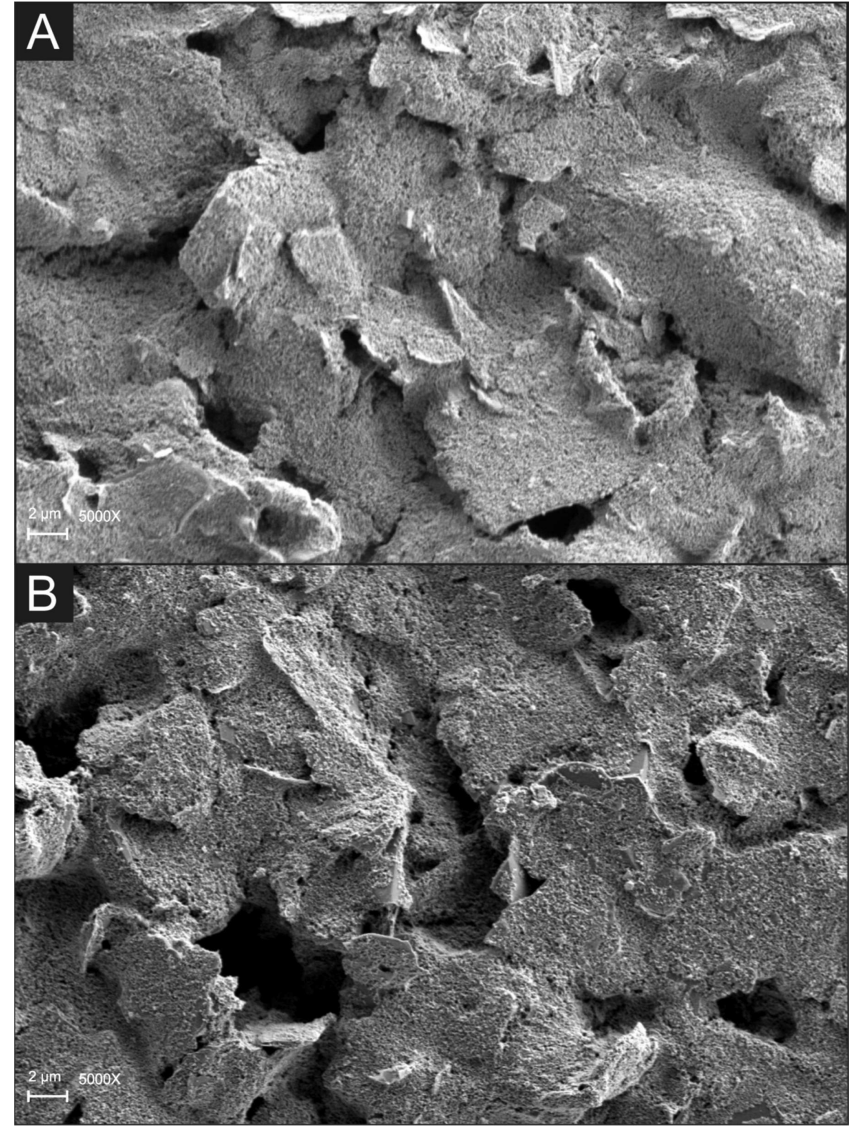

Figure 1. SEM images of untreated (A) and chemically pretreated (B) GSPEs.

and the proportion of $\mathrm{Cl}$ detected showed that similar levels of $\mathrm{C}-\mathrm{O}$ bonds were present in both cases, accounting for approximately $50 \%$ of the intensity of this component. Both spectra showed intensity at approximately $289.3 \mathrm{eV}$, attributed to surface acid groups, $\mathrm{COO}^{-}$. A significant difference was seen at higher binding energy where the treated GSPE sample showed intensity at approximately $291.3 \mathrm{eV}$ not seen on the untreated surface. This is in the spectral region typically associated with graphitic plasmon loss features but is rather intense and suggests the presence of carbon in a further highly chemically shifted configuration such as a carbonate ester, i.e., $\mathrm{R}-\mathrm{O}-\mathrm{C}(=\mathrm{O})-\mathrm{O}-\mathrm{R}$. Note that an inorganic carbonate group such as may be expected from any $\mathrm{Na}_{2} \mathrm{CO}_{3}$ residue would be expected at approximately $289.4-289.5 \mathrm{eV}$, and no significant difference is seen between the untreated and treated samples in this binding energy range. It is clear from the XPS data that the treated surface is more highly oxygenated (higher oxygen surface composition and evidence of a highly oxygenated component in the $\mathrm{C} 1 \mathrm{~s}$ spectrum), but it has not been possible to determine the exact composition of oxygenated species on the GSPE surface.

Electrochemical Testing. Several different accurately measured $0.01 \mathrm{M}$ buffers $(\mathrm{HCl}$, phosphate buffer solution [PBS]) ranging from $\mathrm{pH} 1.76$ to 13.12 were electrochemically tested with square-wave voltammetry (SWV) on both the chemically pretreated GSPEs $\left([10 \% \mathrm{w} / \mathrm{v}] \mathrm{Na}_{2} \mathrm{CO}_{3} / \mathrm{H}_{2} \mathrm{O}_{2}\right)$ and untreated GSPEs. Scanning cathodically from positive to negative potentials, a clear single reduction peak is realized. As can be observed from Figure $2 \mathrm{~A}$, increasing the $\mathrm{pH}$ results in more negative overpotentials as well as there being peaks with 
Table 1. Deconvolution of the XPS Spectra Obtained for the GSPE before and after Chemical Pretreatment (Denoted $\left.\mathrm{Na}_{2} \mathrm{CO}_{3} / \mathrm{GSPE}\right)^{a}$

\begin{tabular}{|c|c|c|c|c|c|c|c|c|}
\hline \multirow[b]{3}{*}{ element } & \multicolumn{4}{|c|}{ GSPE } & \multicolumn{4}{|c|}{ GSPE with pretreatment } \\
\hline & \multirow[b]{2}{*}{ element atom \% } & \multicolumn{3}{|c|}{ moeity } & \multirow[b]{2}{*}{ element atom \% } & \multicolumn{3}{|c|}{ moiety } \\
\hline & & assignment & $\mathrm{BE}(\mathrm{eV})$ & atom $\%$ & & assignment & $\mathrm{BE}(\mathrm{eV})$ & atom $\%$ \\
\hline \multirow[t]{4}{*}{ C $1 \mathrm{~s}$} & 87.2 & $\mathrm{C}-\mathrm{C}$ & 284.7 & 68.86 & 71.1 & $\mathrm{C}-\mathrm{C}$ & 284.7 & 59.08 \\
\hline & & $\mathrm{C}-\mathrm{O} / \mathrm{C}-\mathrm{Cl}$ & 286.55 & 15.63 & & $\mathrm{C}-\mathrm{O} / \mathrm{C}-\mathrm{Cl}$ & 286.58 & 9.92 \\
\hline & & COO- & 288.8 & 2.77 & & $\mathrm{COO}-/ \mathrm{CO}_{3}{ }^{2-}$ & 289.27 & 2.1 \\
\hline & & & & & & plasmon/high oxygenation & 291.09 & 3.53 \\
\hline $\mathrm{Cl} 2 \mathrm{p}$ & 8.8 & $\mathrm{C}-\mathrm{Cl}$ & 200.3 & & 5.6 & $\mathrm{C}-\mathrm{Cl}$ & 200.4 & \\
\hline O $1 \mathrm{~s}$ & 3.9 & unresolved, & stent with & & 16.7 & $\begin{array}{l}\text { broad, consistent with } \mathrm{C} 1 \\
\text { inorganics }\end{array}$ & gnments a & ow level \\
\hline $\mathrm{Na} 1 \mathrm{~s}$ & - & & & & 2.8 & $\mathrm{Na}^{+}$, nonspecific & 1072.4 & \\
\hline Si $2 p$ & - & & & & 1.7 & & & \\
\hline$S 2 p$ & - & & & & 0.4 & & & \\
\hline $\operatorname{Mg} 2 p$ & - & & & & 1.5 & & & \\
\hline $\mathrm{N}$ 1s & - & & & & 0.2 & & & \\
\hline
\end{tabular}

${ }^{a}$ Note the presence of chloride is due to the polyvinyl chloride (PVC) binder in the GSPE ink and the low level additional species found on the pretreated surface make no significant contribution to the interpretation of the carbon surface chemical state as discussed in the text.

much lower intensity; this could be since at high pHs there are less protons available, limiting the amount of species that can be reduced. Note: peaks with lower intensities in acidic conditions ( $>\mathrm{pH} 5$ ) could be attributed to deprotonation of carboxylic acid groups on the surface ${ }^{21}$ or $\mathrm{pH}$ dependent charge trapping of the quinones electrostatically bound in an electrode-confined polymer (polyvinyl chloride [PVC], a polymer, is used as binder in the GSPE ink). ${ }^{22}$ The use of background correction and smoothing were employed by the GPES software to give clarity to the responses, as is common in the literature. ${ }^{4}$ As depicted in Figure S3, there is an electrochemical response with untreated GSPEs, likely due to a small amount of oxygenated species naturally occurring on the GSPE surface; however, note that this is much lower in intensity (approximately 1000 times lower). The use of an untreated electrode provides inconsistent voltammetric responses when utilized to monitor changes in $\mathrm{pH}$ and instead the proposed chemical pretreatment produces optimal responses. The approach herein attempts to negate the use of any mechanical effort as reported in the literature ${ }^{3,4}$ to solely rely on the chemical pretreatment. Note that the chemical pretreatment for a longer duration $(45 \mathrm{~h})$ was explored; however, slight variations in peak current notwithstanding the overwhelming similarities in the response showed $18 \mathrm{~h}$ is adequate for pretreatment (Figure S1).

Next, a plot of peak potential $(E)$ vs $\mathrm{pH}$ was constructed (Figure 2B) where a gradient of $57 \mathrm{mV}$ was observed $(E / V=$ $\left.-57 \mathrm{mV}+0.4 \mathrm{E} / \mathrm{pH}, \mathrm{R}^{2}=0.99\right)$. This value is indicative of a 1:1 proton/electron process as described from the Nernst equation (eq 1). It is important to note that there is no deviation across the $\mathrm{pH}$ range explored. It is hypothesized by $\mathrm{Lu}$ et al. that when bound to the surface, there are significant changes in $\mathrm{p} K_{\mathrm{a}}$ between the bulk aqueous solution and surface immobilized species; naturally leading to the conclusion that the $\mathrm{p} K_{\mathrm{a}}$ value of a selected mediator (in this instance quinones; normal $\mathrm{p} K_{\mathrm{a}}$ value $\sim 9.2$ ) must have been altered, exceeding $\mathrm{pH}$ 13.0 , consequently not changing the linearity of any calibration plots.

As is evident from the literature, new electrodes that are proposed for the sensing of $\mathrm{pH}$ mostly neglect to apply them to the sensing of $\mathrm{pH}$ in "real" unbuffered samples. ${ }^{3,4}$ Consequently, the proposed analytical $\mathrm{pH}$ sensing protocol herein is validated against the laboratory standard glass probe $\mathrm{pH}$ sensor in the "real" unbuffered samples: malt vinegar and a commonly available antacid (Rennies). The electroanalytical SWV signals gained are visible in Figure 3, and comparable values of $\mathrm{pH}$ were obtained in both cases; with malt vinegar a $\mathrm{pH}$ value of 2.98 was obtained by the glass probe compared to 2.86 from the pretreated GSPE $( \pm 0.12$; RSD $3.72 \%)$ and the antacid 10.43 versus $10.08( \pm 0.35 ;$ RSD $4.81 \%)$. This demonstrates there is potential for this approach to be developed into a portable, hand-held, voltammetric $\mathrm{pH}$ sensor using GSPEs.

Returning to the origin of the observed correlation between the voltammetric potential and $\mathrm{pH}$ over the entire $\mathrm{pH}$ range of $1-13$ where no deviation is encountered at alkaline $\mathrm{pH}$ values has previously been reported ${ }^{23-25}$ to be caused by a change in the $\mathrm{p} K_{\mathrm{a}}$ value of a surface immobilized group in comparison to that of a solution phase species. A new alternative approach is proposed herein is that the $\mathrm{p} K_{\mathrm{a}}$ value of a surface bound mediator (oxygenated species) does not interfere with the linear Nernstian response because of its activity $(\alpha)$.

For simplicity, envisage the example of the electrochemical reduction of 1,2-benzoquinone(1,2-BQ) into 1,2-hydroquinone $(1,2-\mathrm{HQ})$ via a 2 -electron and 2-proton process, (Scheme S1) which has been utilized previously in the literature ${ }^{3,4,26}$ (such as Prissanaroon-Ouajai et al. ${ }^{26}$ who used a novel $\mathrm{pH}$ sensor based on hydroquinone monosulfonate-doped conducting polypyrrole). First, consider the Nernst equation which quantitatively predicts the cell potential relating it to the redox behavior of two species, utilized in the above analysis of the electrochemical reduction of $1,2-\mathrm{BQ}$ as described in the following eq 2 :

$$
1,2-\mathrm{BQ}+2 \mathrm{e}^{-}+2 \mathrm{H}^{+} \rightleftharpoons 1,2-\mathrm{HQ}
$$

which when applied to the Nernst equation leads to

$$
E_{\mathrm{p}}=E_{\mathrm{f} / \mathrm{Ox}}^{0}-2.303 \frac{R T}{n F} \log \frac{[\mathrm{Red}]}{[\mathrm{Ox}]}
$$

If one takes into account the activity where $a$ is the symbol for alpha used in all the equations such as in eq 4 of the 1,2benzoquinone (1,2-BQ)/1,2-hydroquinone (1,2-HQ) redox behavior, eq 3 leads to 

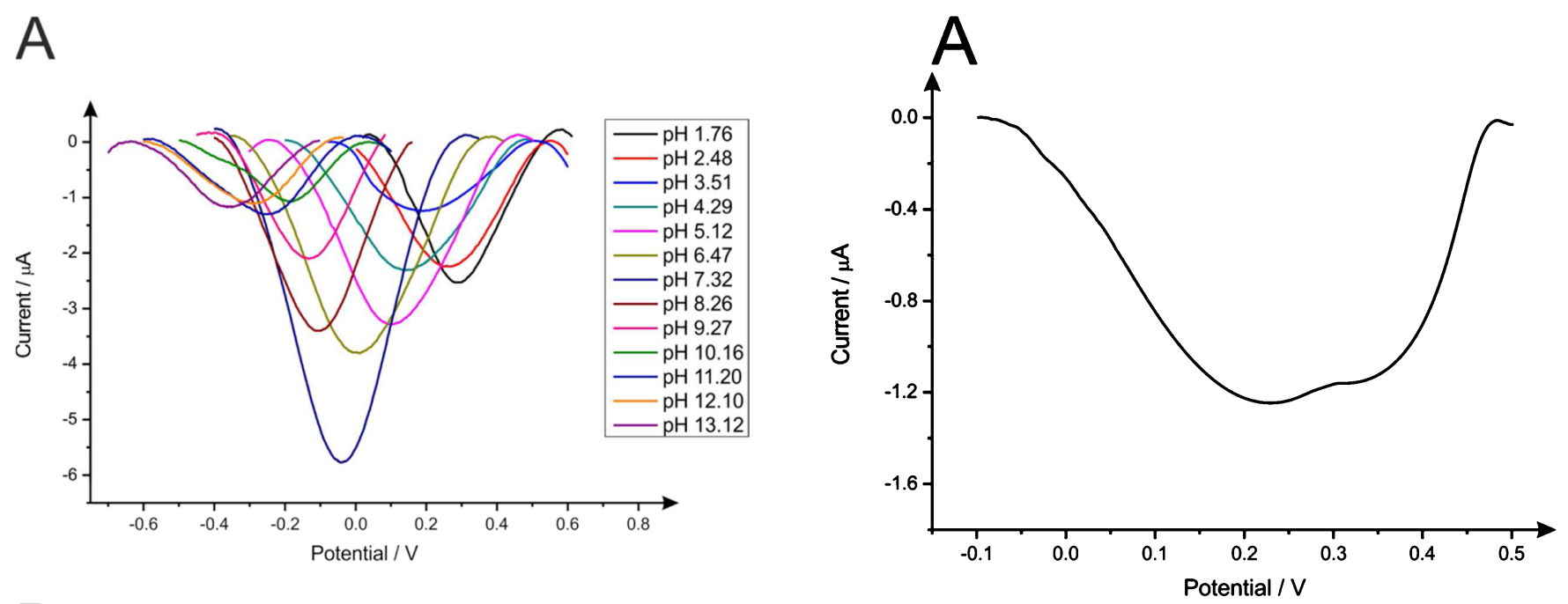

B
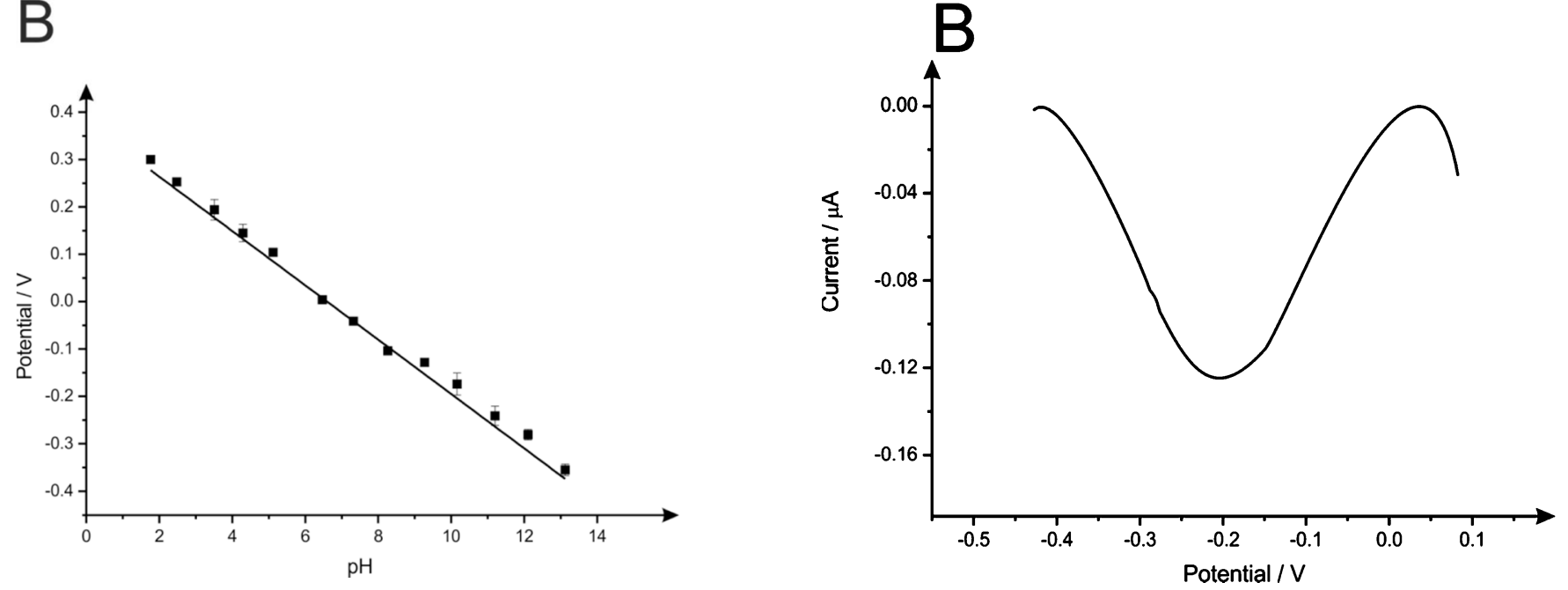

Figure 2. (A) Electrochemical signal (SWV) obtained over the $\mathrm{pH}$ range $1.76-13.12$ using the chemically pretreated GSPEs. Note the electrochemical signal is obtained from scanning the potential from positive to negative to induce the electrochemical reduction of the surface immobilized oxygenated species. SWV parameters: frequency $20 \mathrm{~Hz}$, step potential $2 \mathrm{mV}$, amplitude $200 \mathrm{mV}$ (vs SCE). A new electrode was utilized per subsequent scan. (B) Calibration plot resulting from the analysis of SWV peak potential (data shown in part A) against $\mathrm{pH}$ for using the chemically pretreated GSPEs over the $\mathrm{pH}$ range of 1.76-13.12. A linear response is observed with a gradient of $57 \mathrm{mV} ; R^{2}=0.99 ; N=3$ (vs SCE).

$$
E_{\mathrm{p}}=E_{\mathrm{f} \text { Ox } / \mathrm{Red}}^{0}-2.303 \frac{R T}{2 F} \log \frac{\alpha 1,2-\mathrm{HQ}}{\alpha 1,2-\mathrm{BQ}\left(\alpha \mathrm{H}^{+}\right)^{2}}
$$

However, if it is considered that the surface immobilized groups are a solid since they are immobilized upon the electrode surface and therefore have an activity of 1 ; this results in

$$
\begin{aligned}
& E_{\mathrm{p}}=E_{\mathrm{f} / \mathrm{Red}}^{0}-2.303 \frac{R T}{2 F} \log \frac{1}{\left(a_{\mathrm{H}^{+}}\right)^{2}} \\
& E_{\mathrm{p}}=E_{\mathrm{f}}^{0}{ }_{\mathrm{Ox} / \mathrm{Red}}-2.303 \frac{R T}{2 F} \log \left(a_{\mathrm{H}^{+}}\right)^{-2}
\end{aligned}
$$

Application of the logarithmic power rule results in the following series of equations:

$$
E_{\mathrm{p}}=E_{\mathrm{f}}^{0}{ }_{\mathrm{Ox} / \mathrm{Red}}-2.303 \frac{R T}{2 F}(-2) \log a_{\mathrm{H}^{+}}
$$

Figure 3. Electrochemical signals (SWV) obtained in "real" unbuffered samples for (A) malt vinegar and (B) Rennies antacid using the chemically pretreated GSPEs. SWV parameters: frequency $20 \mathrm{~Hz}$, step potential $2 \mathrm{mV}$, amplitude $200 \mathrm{mV}$ (vs SCE). Peak of maximum inflection is used throughout.

$$
\begin{aligned}
& E_{\mathrm{p}}=E_{\mathrm{f}_{\mathrm{Ox} / \mathrm{Red}}}^{0}+2.303 \frac{R T}{F} \log a_{\mathrm{H}^{+}} \\
& E_{\mathrm{p}}=E_{\mathrm{f} \text { Ox } / \mathrm{Red}}^{0}-2.303 \frac{R T}{F}-\log a_{\mathrm{H}^{+}} \\
& E_{\mathrm{p}}=E_{\mathrm{f} \text { Ox } / \mathrm{Red}}^{0}-2.303 \frac{R T}{F} \mathrm{pH}
\end{aligned}
$$

which show the electrochemical response is dependent solely on the $\mathrm{pH}$ (and obviously other thermodynamic effects, e.g., temperature) and negates the $\mathrm{p} K_{\mathrm{a}}$ values of the quinone species. This offers an alternative explanation as to why there is no change in linearity when surface immobilized oxygenated species (for example, quinone groups) are utilized for $\mathrm{pH}$ sensing. This also explains data obtained by other researchers using oxygenated species immobilized on an electrode surface and solid quinone compounds for $\mathrm{pH}$ sensing which observe similar results of a linear Nernstian response that is dependent only on $\mathrm{pH}$ and not a change in linearity at a surface bound mediators $\mathrm{pK}_{\mathrm{a}}{ }^{3,4,27,28}$ Although this working example (eqs $1-9)$ offers an explanation to the previously mentioned reports, 
the protocol presented within following elucidation of XPS spectra (see above) reveals the process of 1,2-benzoquinone (1,2-BQ) into 1,2-hydroquinone(1,2-HQ) cannot be the sole contributor to the electrochemical response when sensing $\mathrm{pH}$ using the chemical pretreated GSPEs reported above (and perhaps others). An inadequate amount of carbonyl moieties (such as those present on 1,2-BQ) suggest instead that the electrochemical response, which is the origin of the $\mathrm{pH}$ sensor could possibly be dominated, for example, by either

$$
\begin{gathered}
\text { quinone moiety }(\mathrm{R}-\mathrm{C}=\mathrm{O})+2 \mathrm{H}^{+}+2 \mathrm{e}^{-} \\
\rightleftharpoons \text { bisphenol moiety }(\mathrm{R}-\mathrm{C}-\mathrm{OH})
\end{gathered}
$$

or

$$
\begin{aligned}
& \text { hydroquinone moiety }(\mathrm{R}-\mathrm{C}-\mathrm{OH})+\mathrm{H}^{+}+\mathrm{e}^{-} \\
& \rightleftharpoons \text { phenolic moiety }\left(\mathrm{R}-\mathrm{C}-\mathrm{O}^{-}\right)
\end{aligned}
$$

or resonance structures in the graphite lattice; though, as noted above, the exact kinetics of the surface remain unknown and the actual "step by step" mechanism that occurs is likely to be rather complex. What is clear, however, is that it is an equal electron-proton process. Therefore, a generic example of the mathematic resolution is reported below:

$$
\begin{aligned}
& \mathrm{Ox}+n \mathrm{e}^{-}+m \mathrm{H}^{+} \rightleftharpoons \mathrm{Red} \\
& E_{\mathrm{p}}=E_{\mathrm{f}}^{0}-\frac{R T}{n F} \ln \frac{a[\mathrm{Red}]}{a[\mathrm{Ox}] a \mathrm{H}^{+^{m}}} \\
& E_{\mathrm{p}}=E_{\mathrm{f}}^{0}-\frac{R T}{n F} 2.303 \log \frac{a[\mathrm{Red}]}{a[\mathrm{Ox}]}+2.303 \frac{R T}{n F} \log a \mathrm{H}^{+^{+^{m}}} \\
& E_{\mathrm{p}}=E_{\mathrm{f}}^{0}-\frac{R T}{n F} 2.303 \log \frac{a[\mathrm{Red}]}{a[\mathrm{Ox}]}+2.303 \frac{R T m}{n F} \log a_{\mathrm{H}^{+}} \\
& E_{\mathrm{p}}=E_{\mathrm{f}}^{0}-\frac{R T}{n F} 2.303 \log \frac{a[\mathrm{Red}]}{a[\mathrm{Ox}]}-2.303 \frac{m}{n} \frac{R T}{F} \log a_{\mathrm{H}^{+}} \\
& E_{\mathrm{p}}=E_{\mathrm{f}}^{0}-\frac{R T}{n F} 2.303 \log \frac{a[\mathrm{Red}]}{a[\mathrm{Ox}]}-2.303 \frac{m}{n} \frac{R T}{F} \mathrm{pH}
\end{aligned}
$$

This offers an explanation as to why the electrochemical response is dependent only on the $\mathrm{pH}$ and not the $\mathrm{p} K_{\mathrm{a}}$ of a surface immobilized mediator and as such, also explaining the linear response over the entire $\mathrm{pH}$ range observed in this work (Figure 2B) and critically in all prior literature in which this unique response is routinely observed. $3,4,19,20,26$

\section{CONCLUSIONS}

For the first time, the accurate measurement of $\mathrm{pH}$ using chemically pretreated low cost, disposable GSPEs has been shown as a practicable analytical protocol. This inspires the potential for a hand-held, portable, and reproducible $\mathrm{pH}$ sensor that has also been validated against a traditional $\mathrm{pH}$ sensing protocol and demonstrated accurate quantification capabilities when applied to "real" unbuffered $\mathrm{pH}$ samples without the need for further specialized equipment (such as a $\mathrm{pH}$ meter) nor extensive mechanical pretreatment. The monitoring of surface immobilized oxygenated species redox potentials across the range of $\mathrm{pH} 1.76-13.12$ display a linear response $\left(R^{2}=0.99\right)$ with a gradient of $57 \mathrm{mV}(N=3)$. Also presented is an alternative explanation as to why surface immobilized mediators do not influence the Nernstian response; suggesting molecules immobilized on the surface have an activity equal to 1 , excluding them from the Nernst equation meaning the measured potential depends solely on the $\mathrm{pH}$. A mathematical model for all cases involving surface immobilized mediators is proposed in eqs 13-18. This is contrary to previous reports of a mediator immobilized on the surface's $\mathrm{p} K_{\mathrm{a}}$; such work is of huge importance in the electroanalytical field which forms the basis of voltammetric $\mathrm{pH}$ sensors.

\section{ASSOCIATED CONTENT}

\section{S Supporting Information}

The Supporting Information is available free of charge on the ACS Publications website at DOI: 10.1021/acs.analchem.5b01236.

Effect of pretreatment and time of pretreatment on the electrochemical response, XPS spectra, and a sample scheme of one of the many processes potentially occurring in this proposed system (PDF)

\section{AUTHOR INFORMATION}

\section{Corresponding Author}

*E-mail: c.banks@mmu.ac.uk. Phone: +44 (0)161-247-1196. Fax: +44 (0)161-247-6831. Website: www.craigbanksresearch. com.

\section{Notes}

The authors declare no competing financial interest.

\section{ACKNOWLEDGMENTS}

The São Paulo Research Foundation (FAPESP) Grant 2014/ 07705-2 is acknowledged for their financial support on this project. Funding from the British Council in the form of an Institutional link grant (No. 172726574).

\section{REFERENCES}

(1) Deboux, B. J. C.; Lewis, E.; Scully, P. J.; Edwards, R. J. Lightwave Technol. 1995, 13, 1407-1414.

(2) Talaie, A. Polymer 1997, 38, 1145-1150.

(3) Lu, M.; Compton, R. G. Analyst 2014, 139, 2397-2403.

(4) Lu, M.; Compton, R. G. Analyst 2014, 139, 4599-4605.

(5) McMillan, G. K. Chem. Eng. Prog. 1991, 87, 30-37.

(6) Makos, M. A.; Omiatek, D. M.; Ewing, A. G.; Heien, M. L. Langmuir 2010, 26, 10386-10391.

(7) Kampouris, D. K.; Kadara, R. O.; Jenkinson, N.; Banks, C. E. Anal. Methods 2009, 1, 25-28.

(8) Takmakov, P.; Zachek, M. K.; Keithley, R. B.; Bucher, E.; McCarty, G. S.; Wightman, R. M. Anal. Chem. 2010, 82, 9892-9900.

(9) Wildgoose, G. G.; Pandurangappa, M.; Lawrence, N. S.; Jiang, L.; Jones, T. G. J.; Compton, R. G. Talanta 2003, 60, 887-893.

(10) Leventis, H. C.; Streeter, I.; Wildgoose, G. G.; Lawrence, N. S.; Jiang, L.; Jones, T. G. J.; Compton, R. G. Talanta 2004, 63, 10391051.

(11) Lawrence, N. S.; Pagels, M.; Hackett, S. F. J.; McCormack, S.; Meredith, A.; Jones, T. G. J.; Wildgoose, G. G.; Compton, R. G.; Jiang, L. Electroanalysis 2007, 19, 424-428.

(12) Streeter, I.; Leventis, H.; Wildgoose, G.; Pandurangappa, M.; Lawrence, N.; Jiang, L.; Jones, T. J.; Compton, R. J. Solid State Electrochem. 2004, 8, 718-721.

(13) Lafitte, V. G. H.; Wang, W. X.; Yashina, A. S.; Lawrence, N. S. Electrochem. Commun. 2008, 10, 1831-1834.

(14) Banks, C. E.; Compton, R. G. Understanding Voltammetry; World Scientific: Hackensack, NJ, 2007. 
(15) Smith, J. P.; Metters, J. P.; Irving, C.; Sutcliffe, O. B.; Banks, C. E. Analyst 2014, 139, 389-400.

(16) Smith, J. P.; Metters, J. P.; Kampouris, D. K.; Lledo-Fernandez, C.; Sutcliffe, O. B.; Banks, C. E. Analyst 2013, 138, 6185-6191.

(17) Foster, C. W.; Metters, J. P.; Kampouris, D. K.; Banks, C. E. Electroanalysis 2014, 26, 262-274.

(18) Figueiredo-Filho, L. C. S.; Brownson, D. A. C.; Gomez-Mingot, M.; Iniesta, J.; Fatibello-Filho, O.; Banks, C. E. Analyst 2013, 138, 6354-6364.

(19) Dai, C.; Song, P.; Wadhawan, J. D.; Fisher, A. C.; Lawrence, N. S. Electroanalysis 2015, 27, 917-923.

(20) Masheter, A. T.; Abiman, P.; Wildgoose, G. G.; Wong, E.; Xiao, L.; Rees, N. V.; Taylor, R.; Attard, G. A.; Baron, R.; Crossley, A.; Jones, J. H.; Compton, R. G. J. Mater. Chem. 2007, 17, 2616-2626.

(21) Lee, P. T.; Harfield, J. C.; Crossley, A.; Pilgrim, B. S.; Compton, R. G. RSC Adv. 2013, 3, 7347-7354.

(22) Hable, C. T.; Crooks, R. M.; Wrighton, M. S. J. Phys. Chem. 1989, 93, 1190-1192.

(23) Lee, P. T.; Harfield, J. C.; Crossley, A.; Pilgrim, B. S.; Compton, R. G. RSC Adv. 2013, 3, 7347-7354.

(24) Masheter, A. T.; Abiman, P.; Wildgoose, G. G.; Wong, E.; Xiao, L.; Rees, N. V.; Taylor, R.; Attard, G. A.; Baron, R.; Crossley, A.; Jones, J. H.; Compton, R. G. J. Mater. Chem. 2007, 17, 2616-2626.

(25) Abiman, P.; Wildgoose, G. G.; Crossley, A.; Jones, J. H.; Compton, R. G. Chem. - Eur. J. 2007, 13, 9663-9667.

(26) Prissanaroon-Ouajai, W.; Pigram, P. J.; Jones, R.; Sirivat, A. Sens. Actuators, B 2008, 135, 366-374.

(27) Merisalu, M.; Kruusma, J.; Banks, C. E. Electrochem. Commun. 2010, 12, 144-147.

(28) Lawrence, N. S.; Robinson, K. L. Talanta 2007, 74, 365-369. 